Iran Journal of Nursing (IJN)

Vol 34, No. 131, Aug 2021: 31- 43

\title{
Correlations of Self-esteem and Relationship with Parents with Academic Procrastination in Students: An Analytical, Cross-Sectional Study
}

\author{
Mostafa Roshanzadeh ${ }^{1}$, Ali Tajabadi ${ }^{2}$, Bahareh Mazhari Dehkordi ${ }^{3}$, Somayeh Mohammadi $^{4}$
}

\begin{abstract}
Background \& Aims: Procrastination is a very common phenomenon and almost a global problem that exists in all cultures. Studies show that (80-95\%) of students are involved in some form of procrastination and $(50 \%)$ of them are always procrastinating in doing homework and learning subjects. Academic procrastination is one of the factors affecting students' academic achievement and many students cannot use their maximum existential capacity due to this problem. In fact, procrastination causes a high degree of anxiety and depression in the person, which lowers his self-esteem. Self-esteem is one of the most important factors modulating psychosocial stress, which is based on family relationships, academic success, physical image, social interaction, and self-worth. The importance of these issues depends on individual differences and growth. Studies show that the way parents relate to their children and how they raise their children affect procrastination. In addition to common problems of other students, medical students also face special problems in their field, such as the stress of the hospital environment and dealing with the problems of patients, and are more at risk of injury. Therefore, it is necessary to examine different academic problems such as academic procrastination and its related factors including relationship with parents and self-esteem of this group to prevent the academic failure of these students as the future workforce. Training students who, due to academic procrastination, have not been able to acquire sufficient educational competence to provide services to patients will cause several problems in the health system in the future. This study aimed to determine the relationship between self-esteem and relationship with parents with academic procrastination in nursing students.

Materials \& Methods: This predictive, correlational, cross-sectional study was conducted on nursing students of Shahrekord University of Medical Sciences during November-December 2019. The statistical population of this study was all students at the School of Nursing and Midwifery, Shahrekord University of Medical Sciences (nursing, midwifery, operating room, and emergency medicine). In total, 410 students were selected through quota sampling and included in the study. The inclusion criteria were being a student, nursing students in one of the intended disciplines, non-employment in the health system and other organizations. The exclusion criteria were being married, having a history of mental illness and not having parents. The measurement tool was a four-part questionnaire, with the first part related to demographic information (age, gender, field of study, semester, and degree), the second part was Solomon and RothBlum's academic procrastination questionnaire, the third part was Rosenberg's self-esteem questionnaire, and the fourth part of the questionnaire was the parent-child relationships devised by Fine, Moreland, and Schwebe. Data were analyzed in SPSS version 16 using descriptive (mean and standard deviation) and inferential statistics (t-test, one-way ANOVA, Pearson correlation coefficient, and linear regression) at the significance level of 0.05 . The Kolmogorov-Smirnov test was used to evaluate the normal distribution of data, and Levene's test was set as default in t-test. One-way ANOVA was also used to assess the equality of the variances.

Results: Evaluation of the frequency distribution of quantitative variables using the Kolmogorov-Smirnov test showed a normal distribution of data $(\mathrm{P}>0.05)$. In terms of age range, the highest frequency belonged to the age range of 18-32 years and the average age of students in this study was $20.82 \pm 1.83$. Most participants were female.

\footnotetext{
1. Operating Room Department, School of nursing, Shahrekord University of Medical Sciences, Shahrehkord, Iran

${ }^{2}$. Emergency Medical Department, School of paramedicine, Sabzevar University of Medical Sciences, Sabzevar, Iran

3. Operating Room Department, School of nursing, Surgical Technologist, Department of Nursing, Shahrekord University of Medical Sciences, Shahrehkord, Iran

${ }^{4}$. School of nursing, Shahrekord University of Medical Sciences, Shahrehkord, Iran (Corresponding author) Tel:
} 09139803989

Email: s.mohammadi@skums.ac.ir
\end{abstract}


The participants were studying nursing, operating room, emergency medicine, and midwifery, with nursing having the highest ratio. Students in this study were classified into four semesters, with the highest ratio belonging to the first and fifth semesters and the lowest ratio to the third semester. The mean and standard deviation of the academic procrastination score in this study was $64.2 \pm 4.48$ which was moderate. The mean score of relationship with parents was at the desired level of $142.61 \pm 7.11$, and the mean score of self-esteem was $24.12 \pm 1.45$ which was at the average level. Pearson's correlation-coefficient regarding the correlation between the studied variables indicated a negative and significant relationship between academic procrastination with relationship with parents $(\mathrm{P}<0.001 ; \mathrm{r}=-0.54)$ and self-esteem $(\mathrm{P}<0.001 ;-\mathrm{r}=0.32)$. Regression test showed that self-esteem (adjusted $\mathrm{R}^{2}=0.102$ ) and relationship with parents (adjusted $\mathrm{R}^{2}=0.291$ ) significantly predict academic procrastination. The unstandardized beta value showed that the share of self-esteem in predicting academic procrastination was 0.21 , and the share of relationship with parents was 0.27 . Mean scores of self- esteem, relationship with parents, and academic procrastination were $12.24 \pm 1.45,142.61 \pm 7.11$, and $64.2 \pm 4.48$, respectively. The standardized beta value showed that a one-unit increase in the standard deviation of the relationship with parents will decrease the standard deviation of academic procrastination by 0.40 (standardized $\beta=-0.405$ ). 1 unit increase in the standard deviation of the self-esteem variable will decrease the standard deviation of academic procrastination by 0.36 (standardized $\beta=-0.363$ ).

Conclusion: The study aimed to investigate the relationship between self-esteem and relationship with parents with academic procrastination. The results showed that increasing self-esteem and relationship with parents will significantly reduce academic procrastination in students. Self-esteem and relationship with parents also predict academic procrastination. According to these results, it should be said that studying self-esteem and relationship with parents in students is necessary and, these variables should be improved in educational systems with appropriate education, and therefore action should be taken to improve the situation of academic procrastination. The results of this study have some implications for administrators of educational systems to avoid the academic procrastination of medical students whose educational competence is of great importance. Using psychological counseling to assess mental health and its parameters, including self-esteem, helps in identifying students at risk. Also, identifying students' broken relationships with parents through counseling can play an important role in improving their mental health and thus reducing their academic procrastination.

Keywords: Self-esteem, Relationship with Parents, Academic Procrastination, Students, Nursing School

\section{Conflict of Interest: No}

How to Cite: Roshanzadeh M, Tajabadi A, Mazhari Dehkordi B, Mohammadi S. Correlations of Self-esteem and Relationship with Parents with Academic Procrastination in Students: An Analytical, Cross-Sectional Study. Iran Journal of Nursing. 2021; 34(131):31-43.

Received: 8 May 2021

Accepted: 9 Aug 2021 


\title{
رابطه عزت نفس و ارتباط با والدين با اهمالكارى تحصيلى در دانشجويان: يك مطالعه تحليلى - مقطعى
}

\author{
مصطفى روشنز اده '، على تاج آبادى '، بهاره مظهرى دهكردى ‘ّ، سميه محمدى
}

\begin{abstract}
جكيله
مقدمه و هدف: در دانشجويان علوم يزشكى كه صلاحيت آموزشى آنها اهميت خاصى دارد اهمال كارى تحصيلى و عوامل بيشبينى كننده آن از جمله

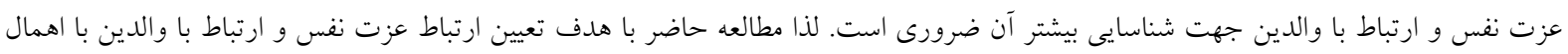

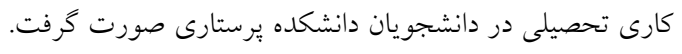

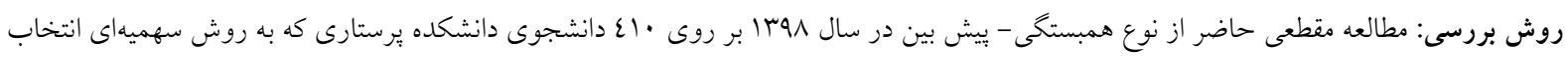

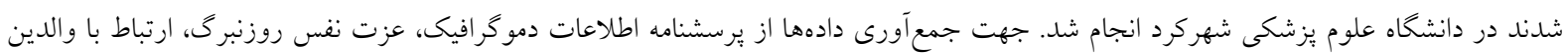

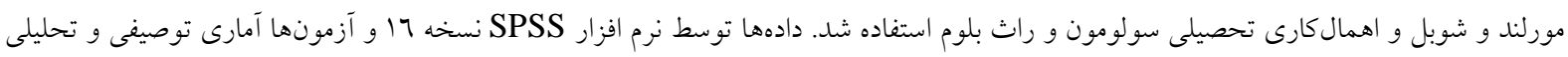
تحليل شد. يافتها: آزمون ضريب همبستخى بيرسون در زمينه ارتباط بين متغيرها حاكى از ارتباط منفى و معنىدارى بين اهمال كارى تحصيلى با ارتباط با والدين

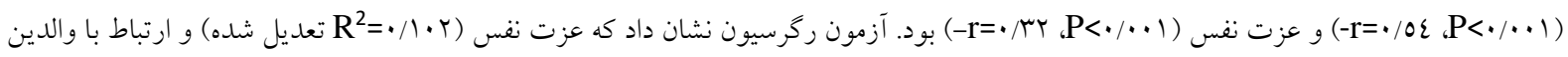

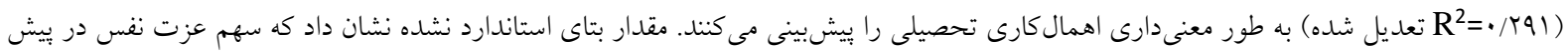

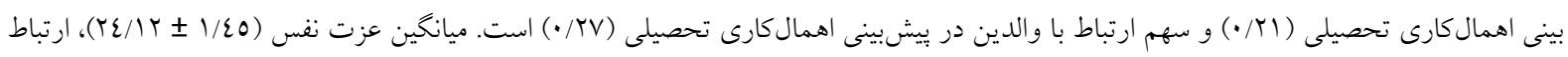

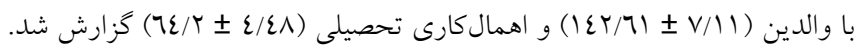

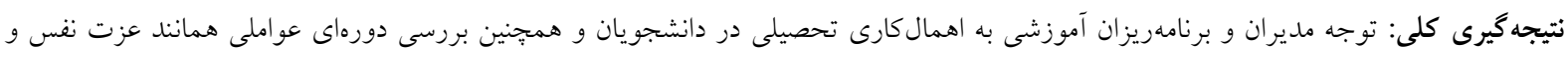

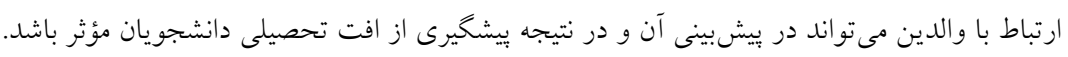

كليد وازهها: عزت نفس، ارتباط با والدين، اهمال كارى تحصيلى، دانشجويان، دانشكده يرستارى

$$
\text { تاريخ دريخ منافع: ندارد }
$$

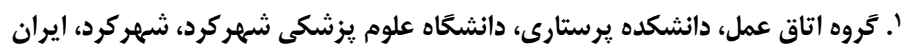

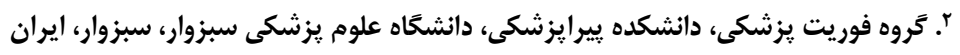

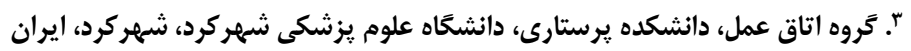

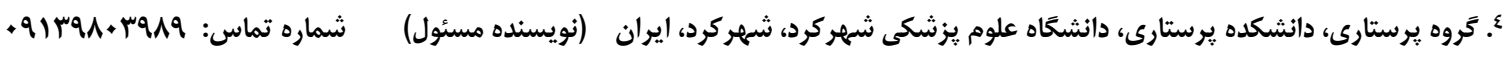


ابعاد مختلف اجتماعى، تحصيلى، خانوادكى و جسمانى

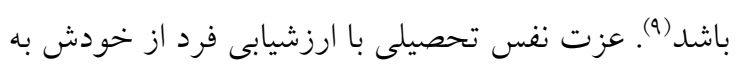

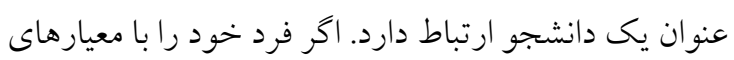
مطلوب تحصيلى منطبق بداند و استانداردهاى ييشرفت

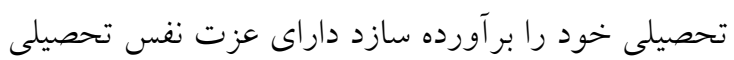

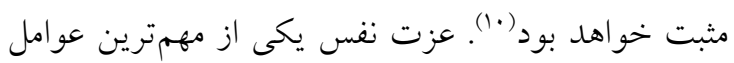

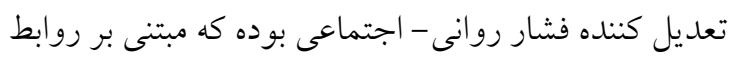

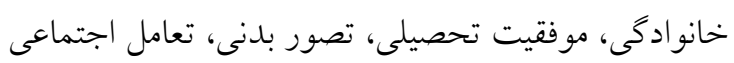
و احساس خود ارزشمندى است كه ميزان اهميت اين زمينه ها بسته به تفاوتهاى فردى و رشد فرد تغيير مى كند (11). ارتباط افراد خانو اده با يكديخر و رعايت بهائ احترام متقابل نيز در عزت نفس و همجنين اهمال كارى تأثير دارد (ז'). خانواده

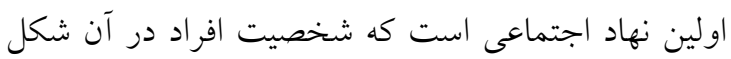

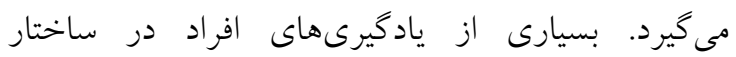

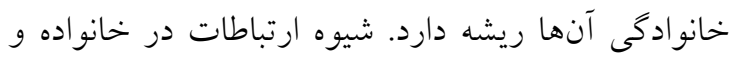

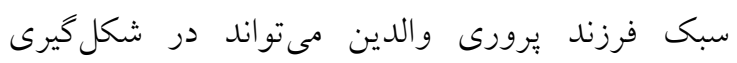

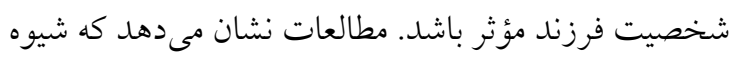

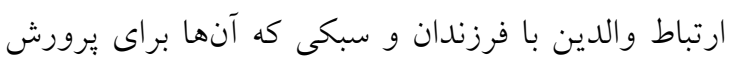
فرزندانشان اتخاذ مىكنند در ايجاد الهمال كارى مؤثر

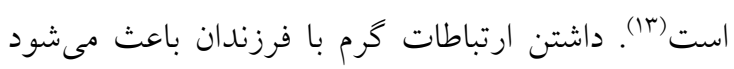

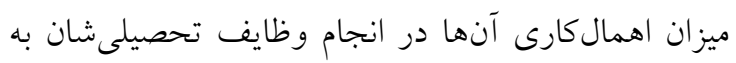

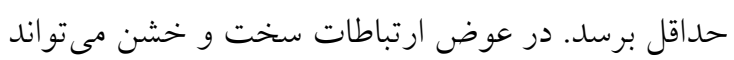

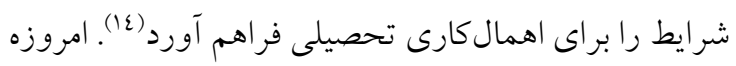

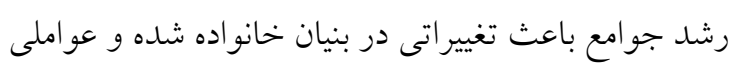

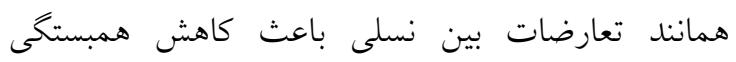

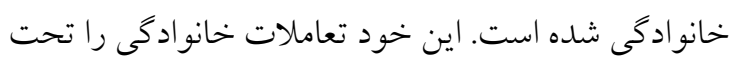

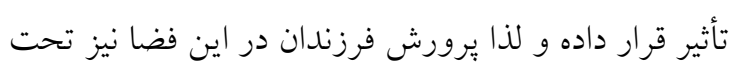

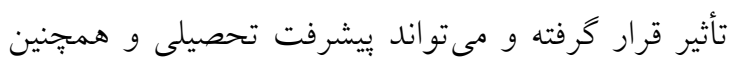

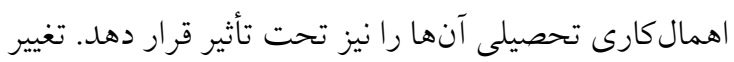
در سبك تعاملى خانواده نيز مىتواند عملكرد تحصيلى نهاني دانشجويان را تحت تأثير قرار دهد (10،عان.). در اين ميان دانشجويان علوم بزشكى به دليل راتيل روبرو دهد شدن

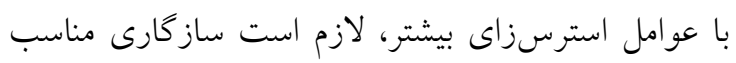

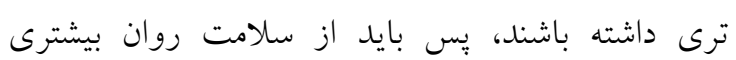

\section{مقدمه}

اهمالكارى تحصيلى (Academic procrastination)

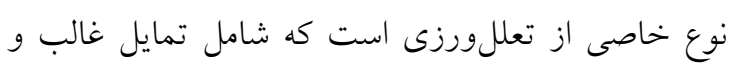

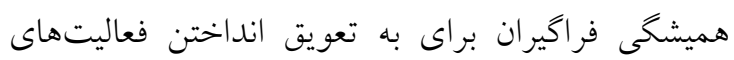

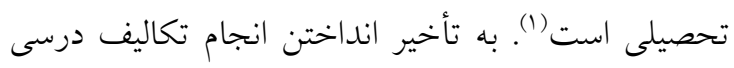
شامل تعللورزى در حضور مداوم در كلاس، آماده شدن آندئ

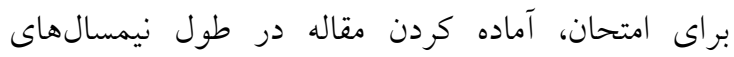
تحصيلى و امور ادارى مربوط به تحصيل تعريف مى شىود (r).

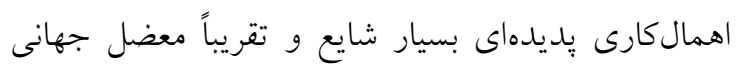

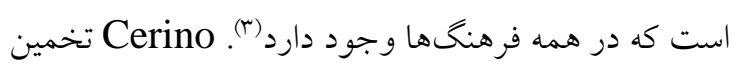
مىزند كه •^ - 90 درصد دانشجويان دانشخاهها به اهمال

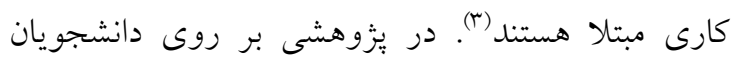

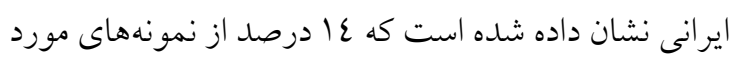
بررسى دجار اهمال كارى شديد و •V درصد دهار اهمال

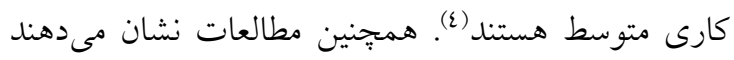

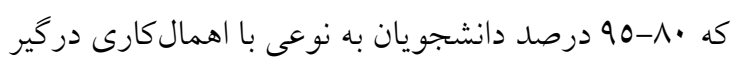
هستند و ·0 درصد آنان همواره در انجام تكاليف و و يادگيرى مطالب درسى اهمال دارند (0.7). اهمالكارى تحصيلى يكى از عوامل تأثير كذار بر بيشرفت دمانت

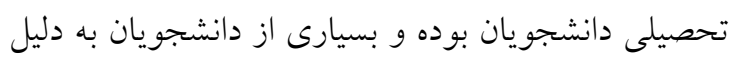

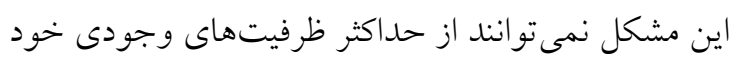

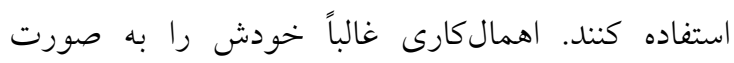

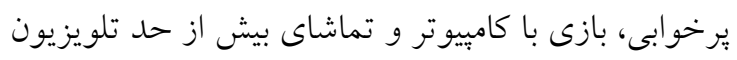
و ساير اشكال اتلاف وقت نمايش مىدهد (ج). دانشجويان بيان كردهاند كه اهمالكارى مىتواند براى آنها ائناد

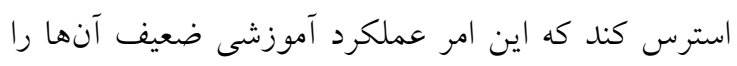

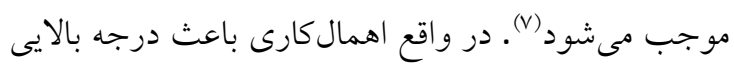

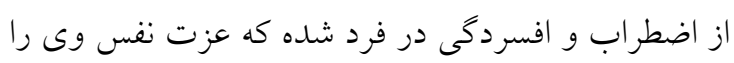

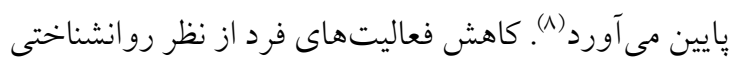
سبب مىشود فرد با تصور شكست در فعاليتهاى مورد

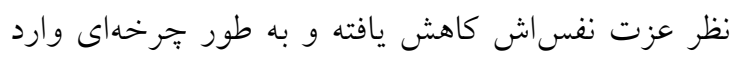
فاز مجدد اهمال كارى تحصيلى شود (7).

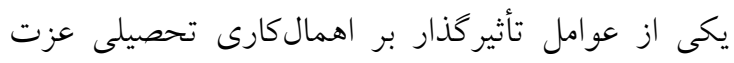
نفس (Self-esteem) است. عزت نفس مى تواند داراى 
تحصيلى و عوامل مؤثر بر آن خصوصاً در دانشجويان گروه

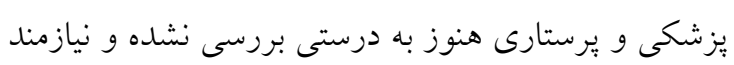
مطالعات بيشتر است (ro.rv).

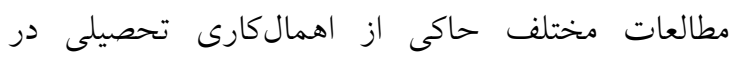

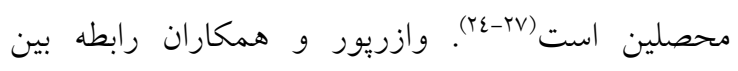

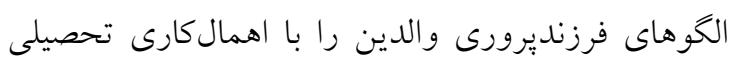

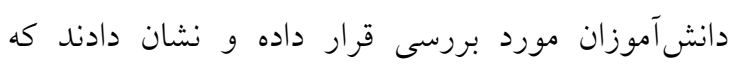

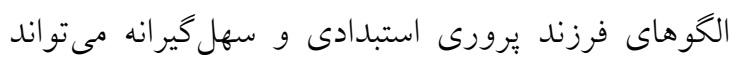

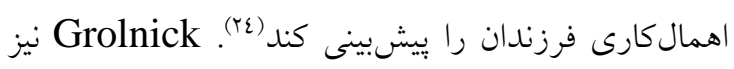

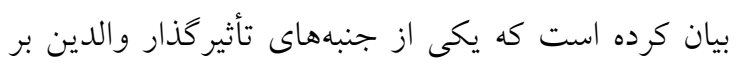

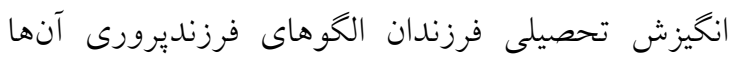

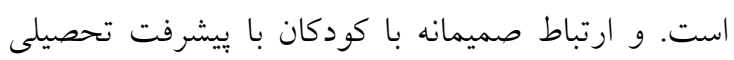

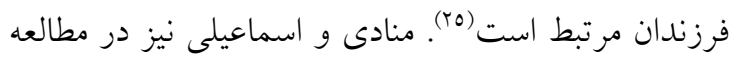

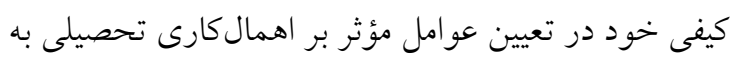
نقش والدين و بيخيرى تكاليف در ايجاد اهمال كارى اشاره

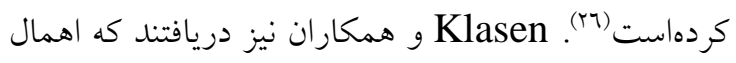
كارى تحصيلى بر عزت نفس افراد تأثير منفى معنىدارى

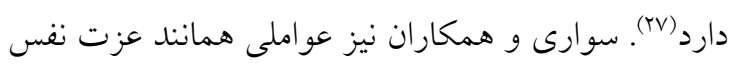

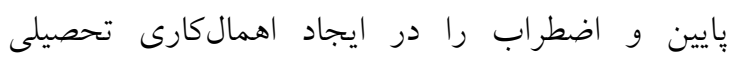

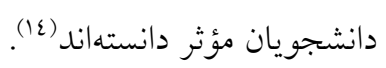

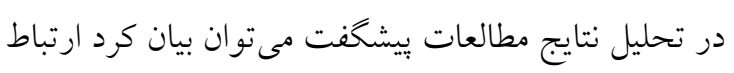

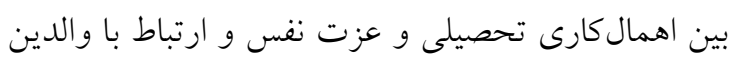

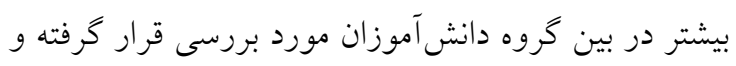

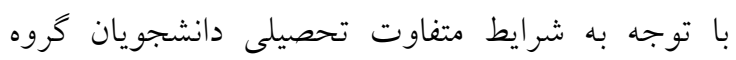

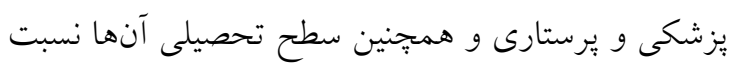

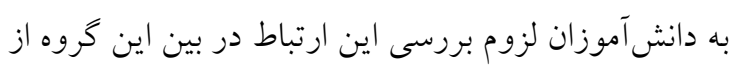

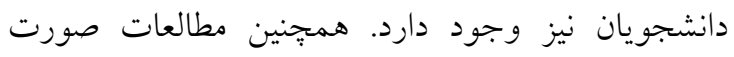
كرفته حاكى از شيوع اهمال كارى تحصيلى در دانشجويان

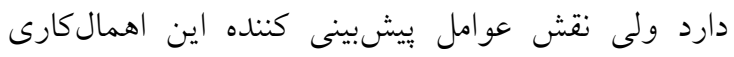

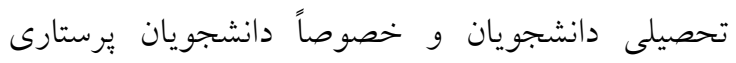
بررسى نشده است. يزوهش حاضر با هدف تعيين رابطه بين ارتباط با والدين و عزت نفس با اهمال كارى تحصيلى برّي

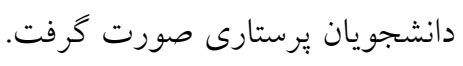

برخوردار باشند تا در تحصيل و در نهايت در حرفه خود

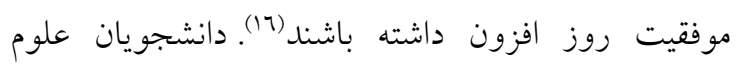
يزشكى علاوه بر مشكلات ساير دانشجويان با مشكلات

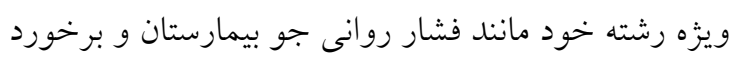

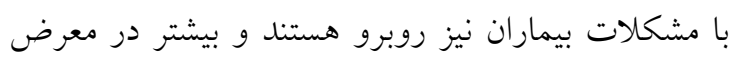

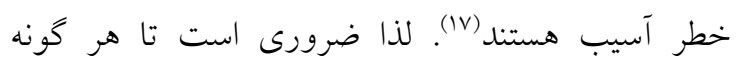

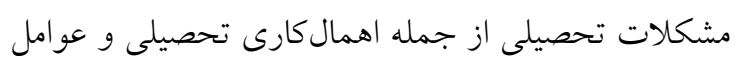

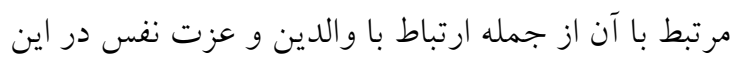

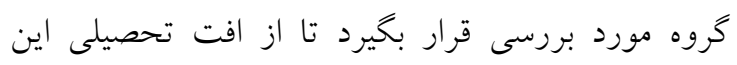

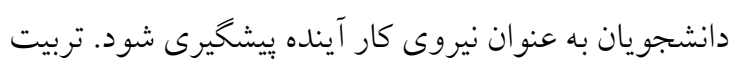

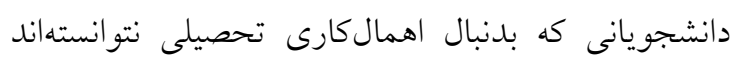

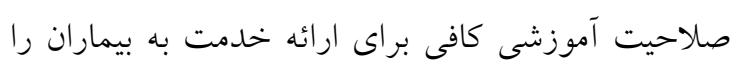
كسب كنند، در آينده سيستم بهداشتى رافي براي ارئه با مشكلات به بيماران

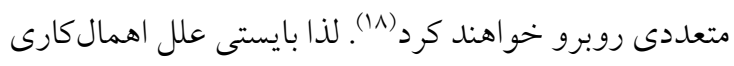

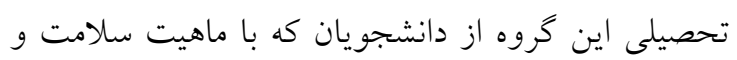

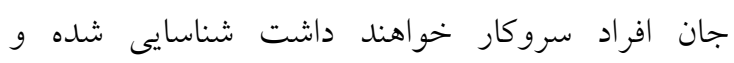
راهكارهاى مناسبى جهت اصلاح آن صورت بخيرد (19). در زمينه جالش موجود در مطالعات مختلف بايستى كفت

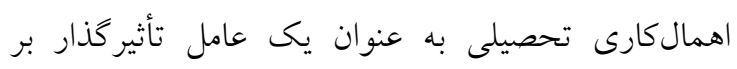

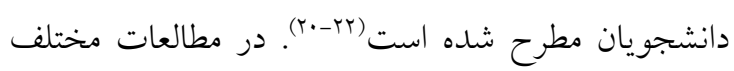

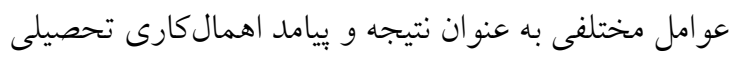

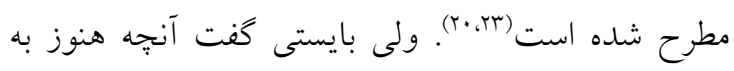

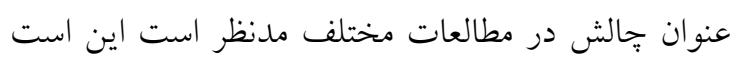

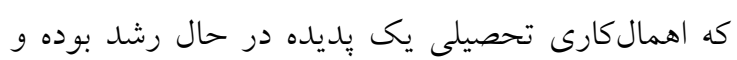

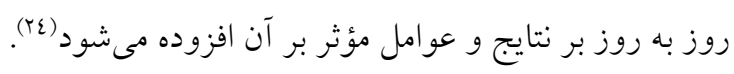
بيان مى كند كه اهمال كارى تحصيلى يك بديده

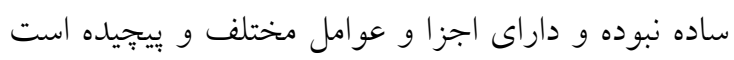

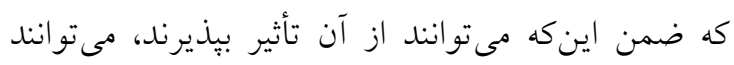

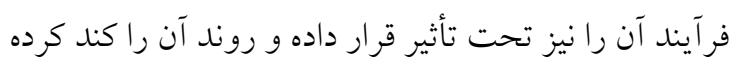
يا تسريع ببخشند. بنابر اين شناسايى عو امل زمينهساز و مؤثر بر اهمال كارى تحصيلى خصوصاً در دانشجويان به عنوان

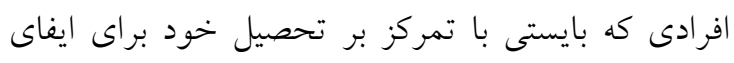

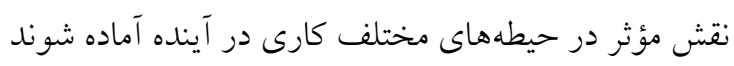

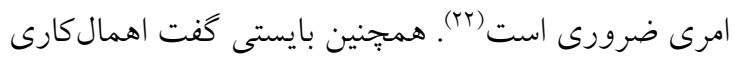


ارتباط با والدين (parent-child relationships) , Schwebel Moreland and Fine براى سنجش اهمال كارى تحصيلى دانشجويان از مقياس

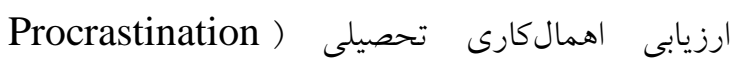
و Rothblum (Assessment Scale-Students rV Solomon كويه در سه حيطه آماده كردن تكليف (11 كويه)، آمادكى

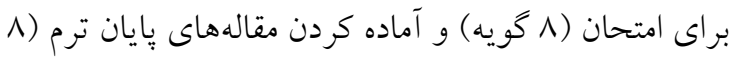
كويه) است. گزينههاى اين برسشنامه مطابق ليكرت ينج

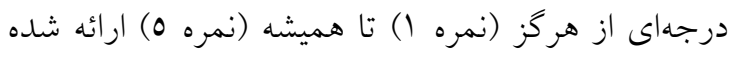

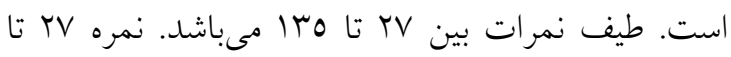

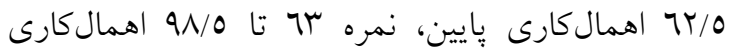

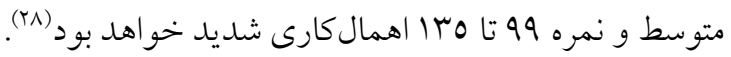
بايايى مقياس اهمال كارى تحصيلى از طريق آلفاى كرونباخ در مطالعه Solomon and Rothblum (1992)، براى

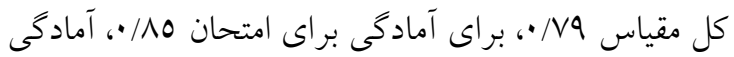

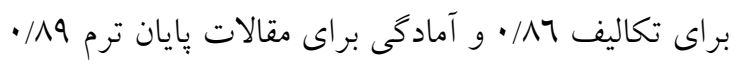

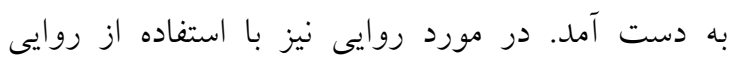

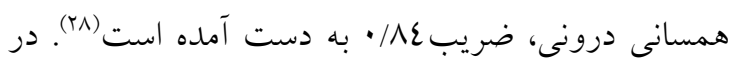

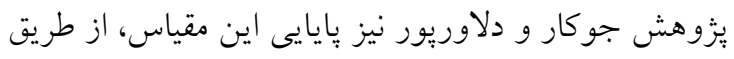

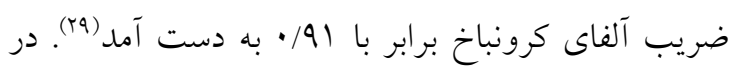

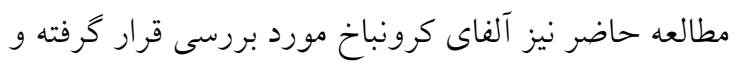

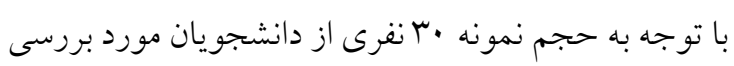
اين مطالعه، 91/ • محاسبه شد.

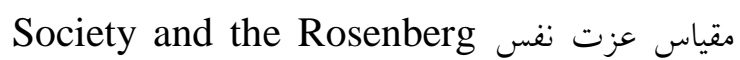
(1970) (adolescent self-image) ارزش يا يذيرش خود را به صورت مثبت بيان مىكند. اين

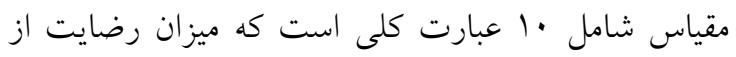
زندكى و داشتن احساس خوب در مورد خود را مى سنجد. يرسشنامه عزت نفس Rosenberg از • لا كويه تشكيل شده است كه داراى دو زير مقياس صلاحيت و شايستخى نهى شخصى (7 سؤال) و رضايتمندى از خود (ع سؤال) است.

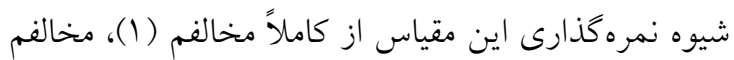

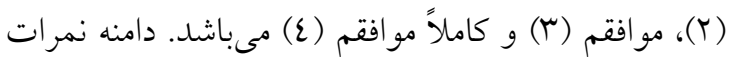

اين يزوهش مقطعى از نوع همبستكى بيش بين است كه دان

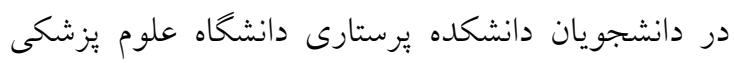

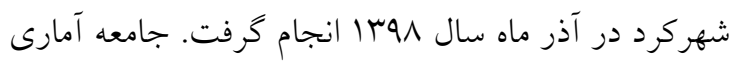
اين ئزوهش همه دانشجويان دانشكده يرستارى دانشخاه

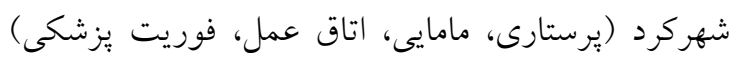

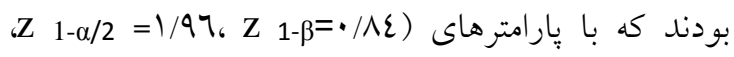

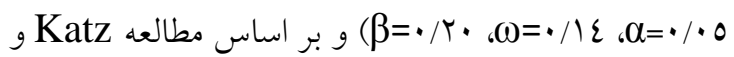

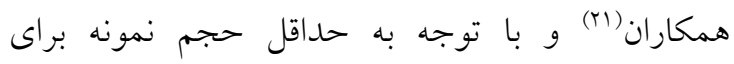

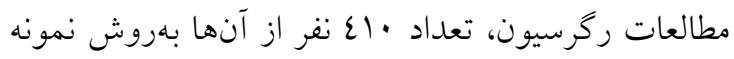

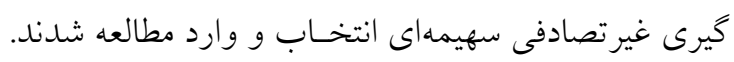

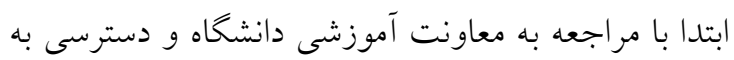

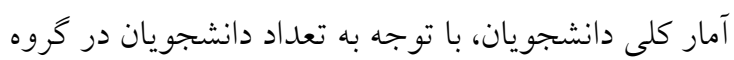

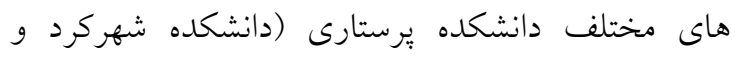
بروجن) براى هر گروه يك سهيمه انتخاب شده و مطابق

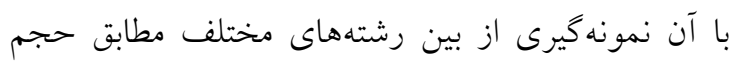

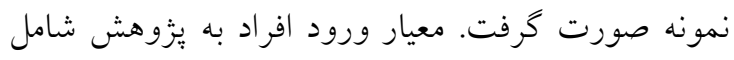
اشتغال فعلى به تحصيل، دانشجويان دانشكده برستارى در درو

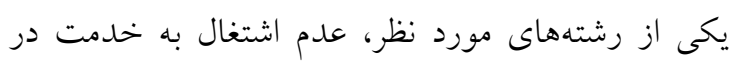

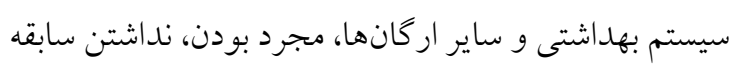

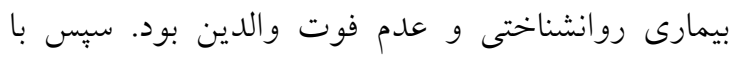

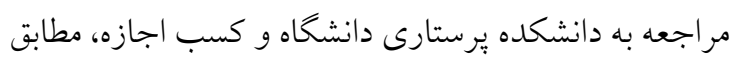

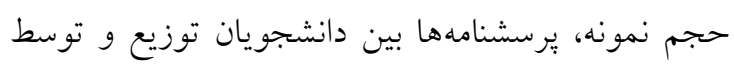

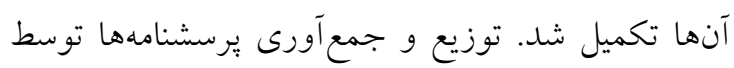

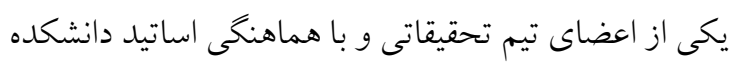

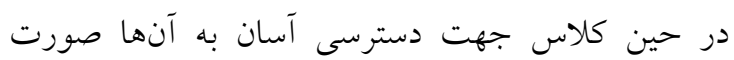
كرفت. ابزار اندازهيرى، يرسشنامه جهار قسمتى بود كه قسمت

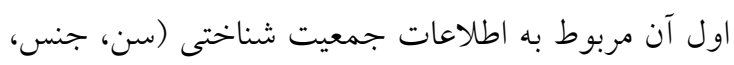
رشته تحصيلى، ترم تحصيلى، مقطع تحصيلى)، قسمت دوم

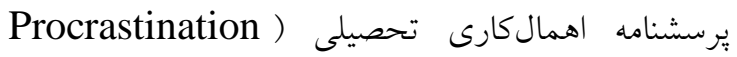
Solomon and Assessment Scale-Students Rothblum Rosenberg (self-image) 
از روش آلفاى كرونباخ براى خرده مقياسهاى مربوط به

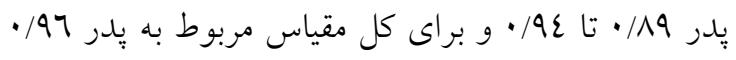

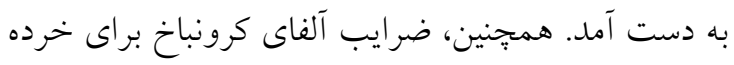

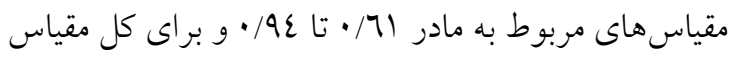

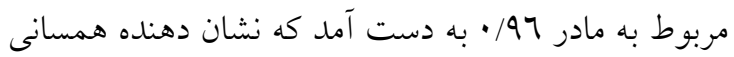

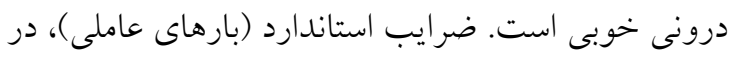

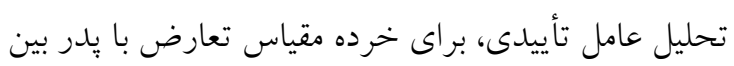

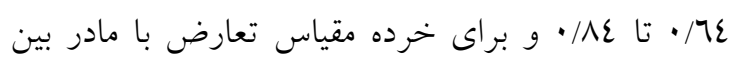

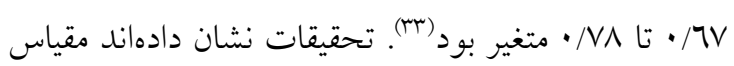

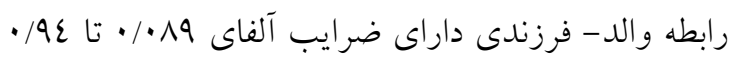

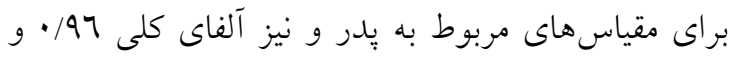

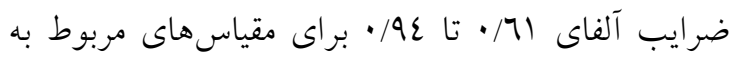

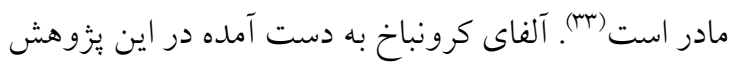

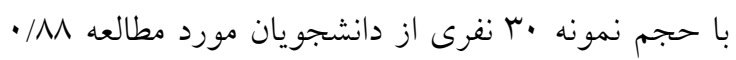

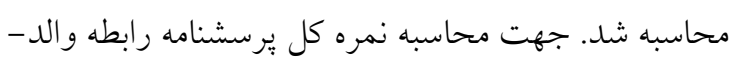

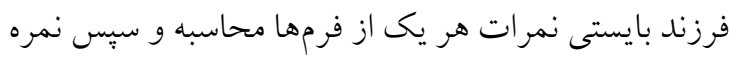

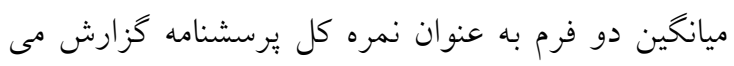

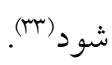
در روند انجام مطالعه موارد اخلاقى مدنظر بزّوهش خر قرار

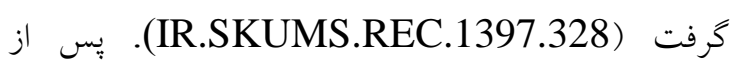
كسب مجوزهاى لازم جهت انجام مطالعه، كسب رضايت

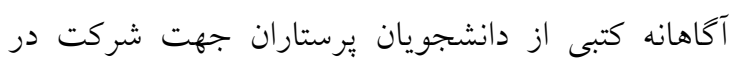
مطالعه و تأكيد بر محرمانكى اطلاعات و آزاد آنداد بودن آنها براى ورود و خروج از مطالعه مدنظر قرار گرفت.

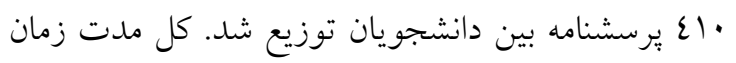

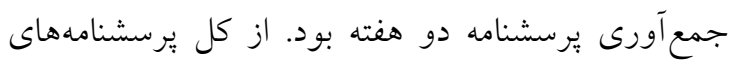

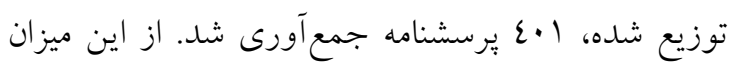

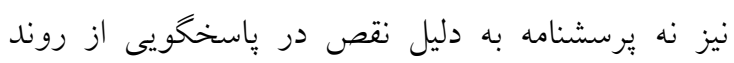

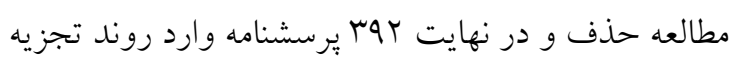
و تحليل آمارى شد. دادهها با استفاده از نرم افزار

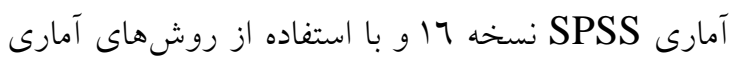
توصيفى (ميانخين، انحراف معيار) و تحليلى (تى دست،

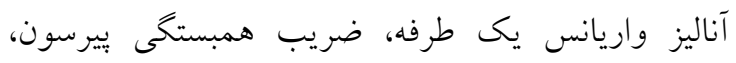
ركرسيون خطى) در سطح معنى دارى 0 • • تجزيه و تحليل
اين مقياس از •ا تا •ع بوده كه نمرات بالاتر نشان دهنده

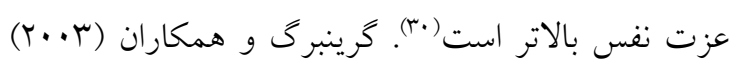
همسانى درونى اين مقياس را عی/· و هايايى آن را با آزمون

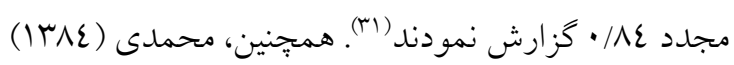

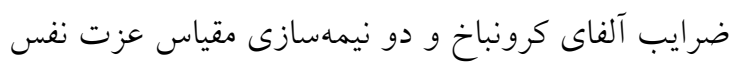

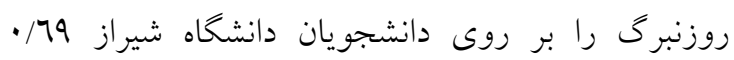

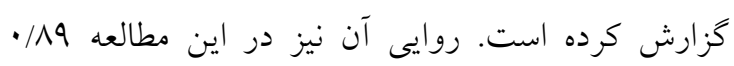

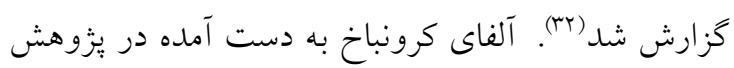
حاضر با حجم نمونه ·ب نفرى از دانشجويان مورد مطالعه درونه / / م محاسبه شد.

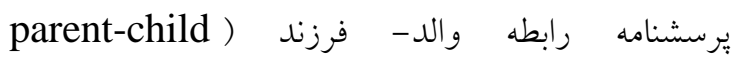
و Moreland Fine براى اولين بار و (relationships Schwebel فرزند تهيه شده است. مقياس رابطه والد- فرزند يك ابزار

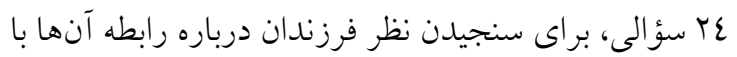

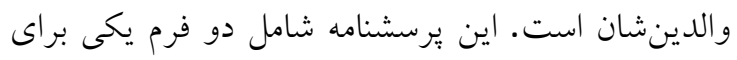

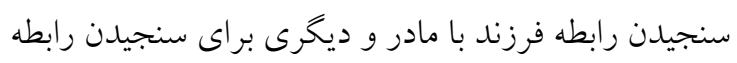

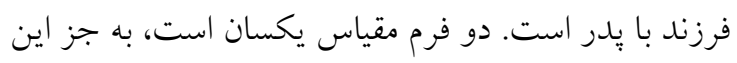

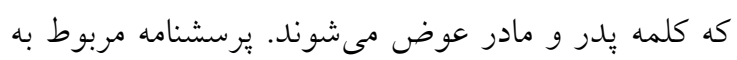

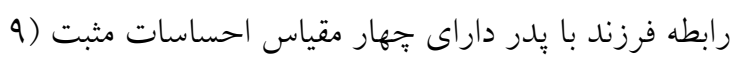

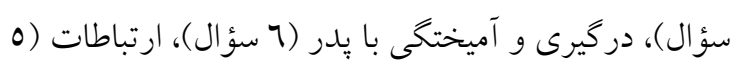

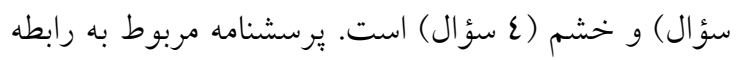
فرزند با مادر داراى جهار حيطه احساسات مثبت (V سؤ ال)،

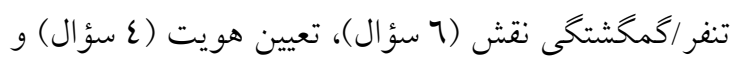

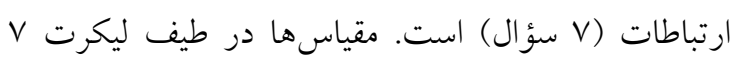
درجهاى از هيج (1) تا خيلى زياد (V) سنجيده مىشود.

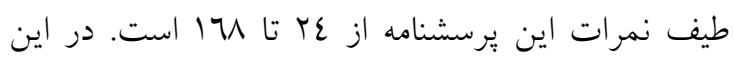

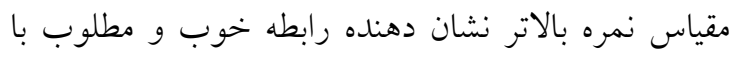

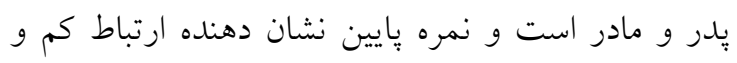
تعارض با والدين است. نمره كل در اين يرسشنامه نشان

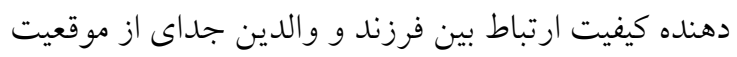

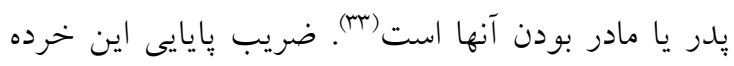

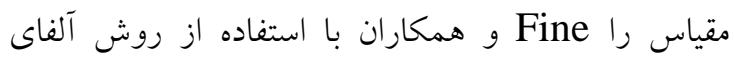
كرونباخ به دست آوردند. ضرايب پايايى مقياس با استفاده 
به دامنه سنى 1/ تا ب سال بودند و ميانخين سن

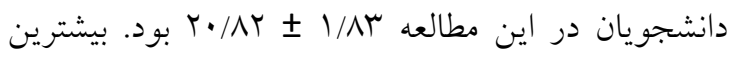
نسبت جنسيتى مربوط به زنان بوده است (NV/O درصد). دانشجويان رشتههاى تحصيلى ״يرستارى، اتاق عمل، فوريت يزشكى و مامايى در مطالعه شركت داشتند كه بيشترين نسبت مربوط به دانشجويان برستارى بود (ع ع/عـ درصد). دانشجويان در اين مطالعه در جهار ترم تحصيلى طبقهبندى شدهاند كه بيشترين نسبت را ترم يك (0V/O درصد) و ينج (T/T/T درصد) و كمترين نسبت را ترم سه

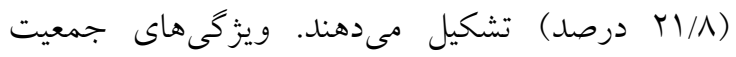
شناختى دانشجويان مورد مطالعه در جدول شماره 1 كزارش شده است.
شدند. براى بررسى نرمال بودن توزيع دادهها از آزمون كولمو گروف- اسميرنوف (Kolmogorov-Smirnov) استفاده شد. براى بررسى تساوى واريانسها از آزمون لوين

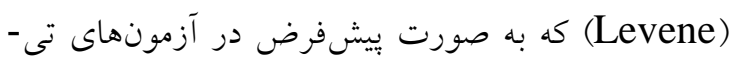
تست و آناليز واريانس يكعرفه وجود دارد استفاده شد. سطح معنى دارى در آزمونها ه • • در نظر كرفته شد.

\section{إفتهها}

ارزيابى توزيع فراوانى متغيرهاى كمى با استغاده از آزمون كولمو گوروف- اسميرنوف حاكى از توزيع نرمال دادهها بود (0/ • P>). از نظر دامنه سنى بيشترين فراوانى مربوط

جدول شماره ا: مقايسه ميانكَين نمرات اهمال كارى تحصيلى، ارتباط با والدين و عزت نفس بر حسب ويزَّىهاى جمعيت شناختى در

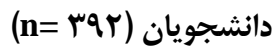

\begin{tabular}{|c|c|c|c|c|c|c|c|}
\hline 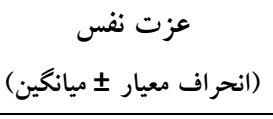 & 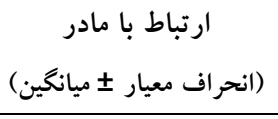 & 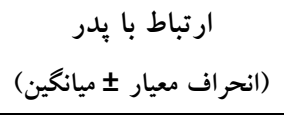 & (انحراف معيار \ميانغين) & درصد & تعداد & & متغير \\
\hline$r \mu / l \pm \cdot v / M r$ & $1 \% \cdot / 0 \pm \cdot v / \cdot 1$ & $\mid r \varepsilon / 0 \pm 1 V / 9 r$ & $7 \cdot / 1 \varepsilon \pm 1 / 07$ & $1 T / 0$ & $\varepsilon 9$ & مرد & جنسيت \\
\hline$r V / 0 \pm I V / T r$ & $\|\varepsilon / V \pm\| / \Lambda r$ & $1 \varepsilon q / \varepsilon \pm r / 1 r$ & $V\urcorner / V \pm \varepsilon / \varepsilon \varepsilon$ & $\Lambda V / O$ & r々r & زن ان & \\
\hline$P=\cdot / 171$ & $\mathrm{P}=\cdot / \cdot 9 \mathrm{r}$ & $P=\cdot / \pi q \wedge$ & $\mathrm{P}=\cdot / r \varepsilon r$ & \multirow{2}{*}{\multicolumn{3}{|c|}{ 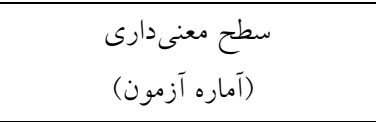 }} & \\
\hline$(t=r / 0 V)$ & $(t=\varepsilon / I V)$ & $(t=r / T V)$ & $(\mathrm{t}=r / r r)$ & & & & \\
\hline$r \mathrm{~T} / \mathrm{T} \pm \mathrm{rV/T}$ & $11 r / 7 \pm r 1 / 1 r$ & $\mid r Y / \varepsilon \pm T / 70$ & $\varepsilon V / V \pm O r / 10$ & $r \varepsilon / \varepsilon \varepsilon$ & Iro & يرستارى & ر رشته \\
\hline$r Y / T \pm I T / Y T$ & $\| r \cdot / r \pm T / v o$ & $1 r \tau / q \pm \varepsilon \tau / v V$ & $\varepsilon 1 / V \pm \cdot \varepsilon / \varepsilon \varepsilon$ & $r \cdot / 91$ & $\Lambda r$ & مامايى & تحصيلى \\
\hline$r \Lambda / r \pm 1 \varepsilon / 7 r$ & $1 \cdot r / 11 \pm 7 / r_{0}$ & $97 / r \pm \cdot T / V V$ & $79 / 9 \pm 1 r / \cdot \varepsilon$ & $r \cdot / \mu r$ & 119 & اتاق عمل & \\
\hline$r \pi / r \pm 1 / 9 r$ & $1 \varepsilon r / \varepsilon \pm 1 Y / 90$ & $\mid r O / \Lambda \pm \wedge \varepsilon / / \Lambda$ & $\Lambda \cdot / 1 \pm 9 \vee / 09$ & $1 \varepsilon / T q$ & 07 & فوريت يزشكى & \\
\hline $\mathrm{P}=\cdot / .91$ & $\mathrm{P}=\cdot / \cdot \vee \wedge$ & $\mathrm{P}=\cdot / \cdot 01$ & $\mathrm{P}=\cdot / 794$ & \multirow{2}{*}{\multicolumn{3}{|c|}{$\begin{array}{l}\text { سطح معنى (آماره آزمون) } \\
\end{array}$}} & \\
\hline$(\mathrm{F}=\varepsilon / 1 \cdot)$ & $(F=r / 9 \varepsilon)$ & $(F=r / l \varepsilon)$ & $(F=\varepsilon / N \wedge)$ & & & & \\
\hline $11 / 1 \pm 17 / 90$ & $\mid \varepsilon V / V \pm 1 \varepsilon / \bullet \wedge$ & $\| r V / V \pm q \varepsilon / \cdot \wedge$ & $q \cdot / \Lambda \pm V T / \cdot \varepsilon$ & $\mathrm{rV} / \cdot 0$ & 11. & 1 & 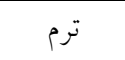 \\
\hline$r \varepsilon / T \pm O V / T V$ & $I Y V / V \pm 99 / 1 \wedge$ & $\mid r V / \| \pm T V / r \wedge$ & $00 / V \pm \wedge V / \cdot q$ & $r \mid / \Lambda$ & $\wedge \vee$ & r & تحصيلى \\
\hline$r \varepsilon / r \pm 1 \Lambda / v r$ & $\mid r V / \varepsilon \pm 9 \varepsilon / \varepsilon \wedge$ & $\mid Y T / 9 \pm M N / 1 \varepsilon$ & $V \cdot / V \pm 9 V / \cdot 9$ & $r \Lambda / T$ & $1 \cdot r$ & 0 & \\
\hline$r \varepsilon / \backslash \pm \varepsilon V / q r$ & $11 V / 0 \pm \cdot \varepsilon / 01$ & $\mid r N / V \pm 1 \varepsilon / 10$ & $\Lambda \cdot / r \pm q V / r q$ & rT/00 & 94 & v & \\
\hline $\mathrm{P}=. \cdot / .01$ & $\mathrm{P}=\cdot / \pi \mu \varepsilon$ & $\mathrm{P}=\cdot /|\mu|$ & $\mathrm{P}=\cdot / 7 r \mid$ & \multirow{2}{*}{\multicolumn{3}{|c|}{ 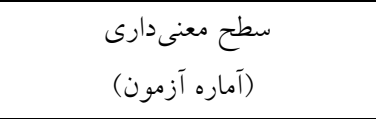 }} & \\
\hline$(F=\varepsilon / \backslash \varepsilon)$ & $(\mathrm{F}=\mathrm{V} / \mathrm{\Lambda})$ & $(F=7 / 11)$ & $(F=r / T r)$ & & & & \\
\hline$r r / r \pm V V / q r$ & $\mid r T / 7 \pm V Y / O r$ & $|\varepsilon r / \Lambda \pm \cdot r /| \Lambda$ & $\Lambda \varepsilon / \neg \pm r V / \mu\urcorner$ & $9 T / T \varepsilon$ & rat & ل ليسانس & سطح \\
\hline$r Y / Y \pm 10 / \cdot 7$ & $\mid \varepsilon r / \Gamma \pm O r / \varepsilon \wedge$ & $M N / O \pm M O / T \Lambda$ & $T r / V \pm \cdot V / 10$ & $V / 77$ & $r$. & فوق ليسانس & تحصيلات \\
\hline $\mathrm{P}=\bullet / 1$ & $\mathrm{P}=\cdot / 10 \mathrm{~V}$ & $\mathrm{P}=\cdot / 70 \mathrm{~V}$ & $\mathrm{P}=\cdot / T V$ & \multirow{2}{*}{\multicolumn{3}{|c|}{$\begin{array}{l}\text { سطح معنى دارى (آماره آزمون) } \\
\text { آزون) }\end{array}$}} & \\
\hline$(t=r / \mid 0)$ & $(\mathrm{F}=\mathrm{V} / \cdot \mathrm{T})$ & $(F=r / r\urcorner)$ & $(F=1 / .9)$ & & & & \\
\hline
\end{tabular}




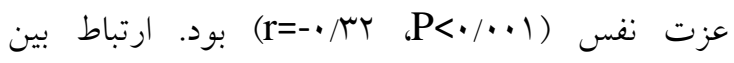

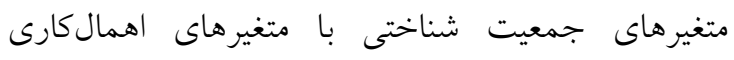

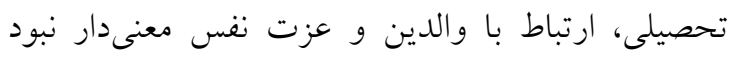

$(\mathrm{P}>\cdot / \cdot 0)$

جهت بيشبينى اهمالكارى تحصيلى از طريق ارتباط با بان

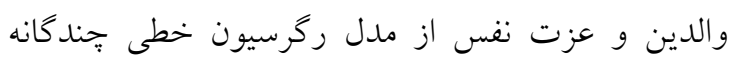

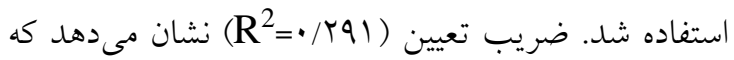

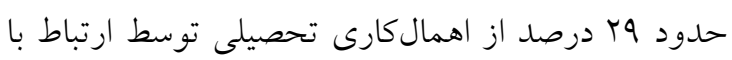
والدين قابل ييشبينى است. همرجنين ضريب تعيين نشان مى دها كه حدود ·ل ادرصد از اهمال كارى تحصيلى توسط عزت نفس قابل ييشبينى است.

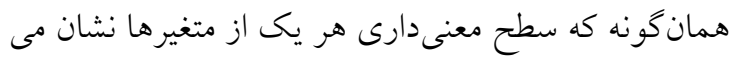

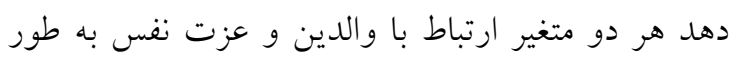
معنى دارى اهمالكارى تحصيلى را بيشبينى مى كنند

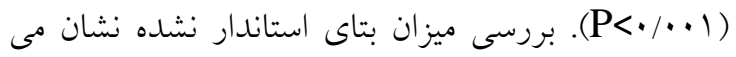
دهد كه هر متغير جه سهمى در ييشبينى متغير مورد نظر

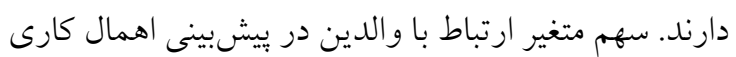

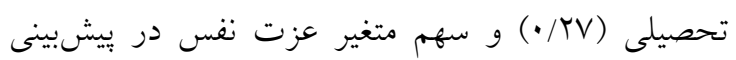

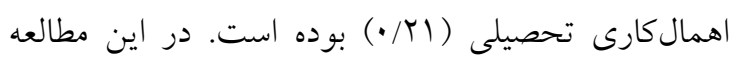

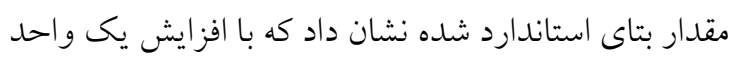

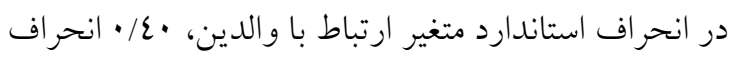

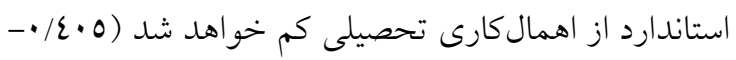
及=

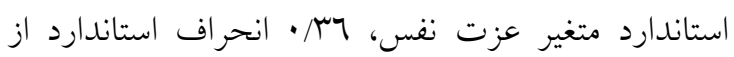

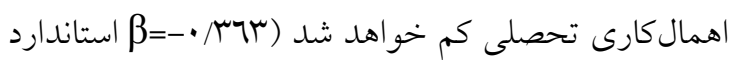

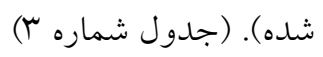

ميانخين و انحر اف معيار نمره اهمال كارى تحصيلى در اين

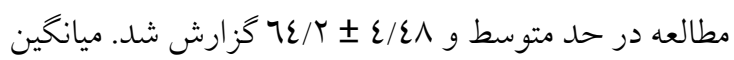

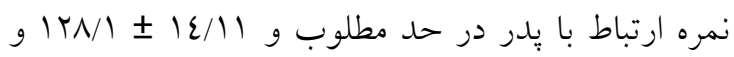

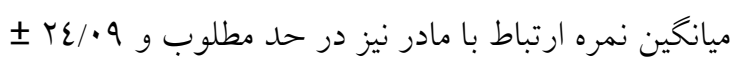
loV/T

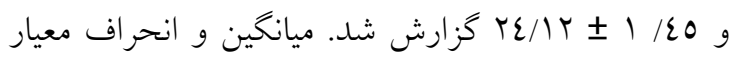
ابعاد مختلف اين متغيرها در جدول شماره r ارائه شده

جدول شماره r: ميانغَين و انحراف نمره اهمال كارى تحصيلى،

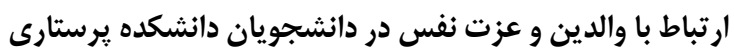

(n=rq $)$

\begin{tabular}{|c|c|c|c|}
\hline انحر اف معيار & متغير & & رديف \\
\hline$V / / \Lambda \pm 10 / 2 \Lambda$ & آماده كردن تكليف & & 1 \\
\hline $00 / \Gamma \pm \varepsilon / \varepsilon 1$ & آمادگى براى امتحان & اهمال كارى & \\
\hline \multirow[t]{2}{*}{$7 \varepsilon / 0 \pm .0 / .0$} & آماده كردن مقالههاى & تحصيلى & \\
\hline & لِيان ترم & & \\
\hline $7 \varepsilon / \varepsilon \pm r / \varepsilon \Lambda$ & كل & & \\
\hline$|r \wedge / 1 \pm| \varepsilon / \|$ & ارتباط با يدر & ارتباط با & r \\
\hline $10 V / r \pm r \varepsilon / .9$ & ارتباط با مادر & و والدين & \\
\hline \multirow[t]{2}{*}{ YN/IT $\pm 1 / 20$} & صلاحيت و شايستكى & & r \\
\hline & شخصى & عزت نفس & \\
\hline$r \cdot / r \pm 1 / 20$ & رضايتمندى ازخود & & \\
\hline$r \varepsilon / T \pm 1 / \varepsilon 0$ & كل & & \\
\hline
\end{tabular}

آزمون ضريب همبستكى بيرسون در زمينه ارتباط بين

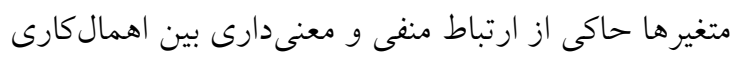

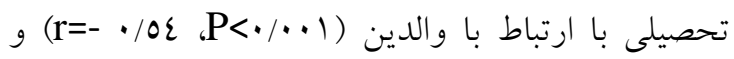

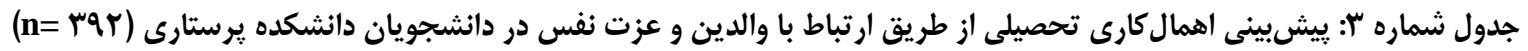

\begin{tabular}{|c|c|c|c|c|c|c|c|c|}
\hline (ADJ) تعديل شده R2 & مقدار R & مقدار R & p-value & مقدار t & $\begin{array}{c}\boldsymbol{\beta} \\
\text { استاندارد شده }\end{array}$ & خعار & $\begin{array}{c}\boldsymbol{\beta} \\
\text { استاندارد نشده }\end{array}$ & متغيرهاى بيش \\
\hline \multirow[t]{3}{*}{$\cdot / r 11$} & $\cdot / 791$ & $-\cdot / 0 \varepsilon$ & $<\cdot / \cdot \cdot \mid$ & $11 / \varepsilon V$ & - & $O / A V$ & $\varepsilon Q / 7 V$ & مقدار ثابت \\
\hline & & & $<\cdot / \cdot \cdot$ & $-\varepsilon / \cdot\urcorner$ &.$- / 2 \cdot 0$ &.$/ .0 \varepsilon$ & $-\cdot / r V r$ & ارتباط با يدر \\
\hline & & & $<\cdot / \cdot \cdot$ & - & $-\cdot r \varepsilon 0$ & $\cdot / \pi \xi$ & $-\cdot / 1 \wedge 9$ & ارتباط با مادر \\
\hline \multirow[t]{2}{*}{.$/ .97$} & $\cdot / 1 \cdot r$ & $-\cdot / \Gamma T$ & $<\bullet \bullet \cdot)$ & $1 \cdot / 47$ & - & $T / N r$ & $T Y / \mu r$ & مقدار ثابت \\
\hline & & & $<\cdot / \cdot \cdot 1$ & $-r / 77$ & זרזי- & $.1 \cdot 7$. & $-\cdot / r \mid r$ & عزت نفس \\
\hline
\end{tabular}


شوند. پِ شايد بتوان كفت وقتى دانشجويان انتظارى براى بحث و نتيجه كيرى

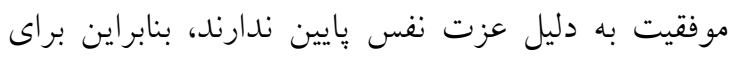
دستيابى به اهداف تحصيلى خود تلاش نخواهند كرد. Rosario و همكاران در كشور يرتغال يكى از عوامل مؤثر

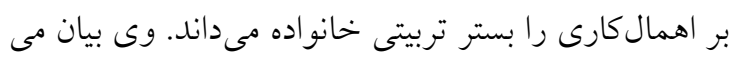
كند خانو ادهها بر عوامل شخصيتى و تربيتى فرزندان تأثير

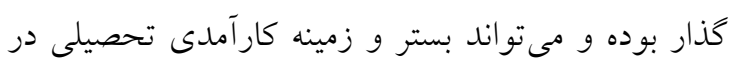

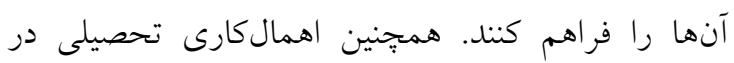

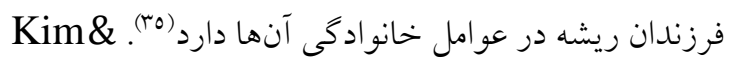

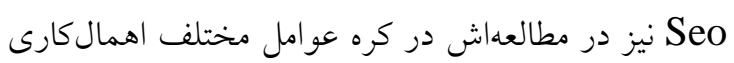

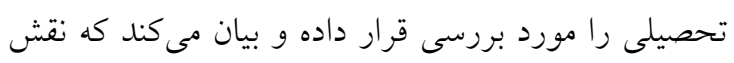
عوامل خانواده در اين زمينه انكار نايذير است. در اين ميان عوامل ميانجيگرى مختلفى نيز وجود دارد كه با توجه به ديه

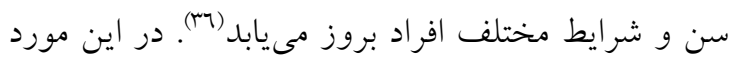

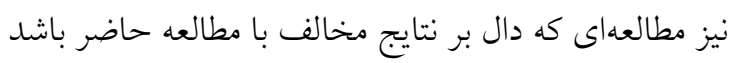

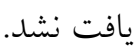

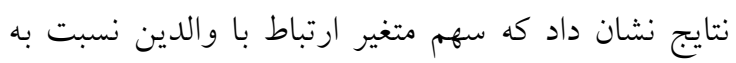
عزت نفس در بيش بينى اهمال كارى تحصيلى بيشتر بوده

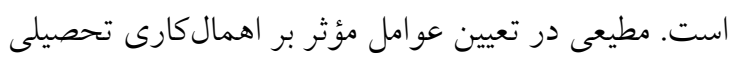

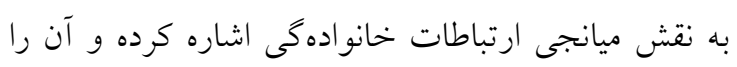

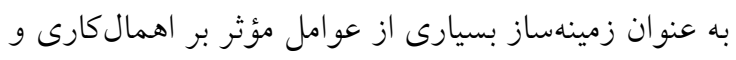

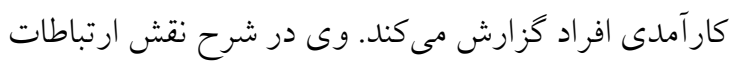

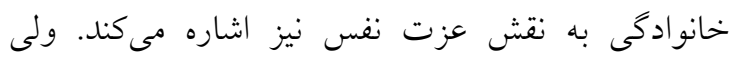

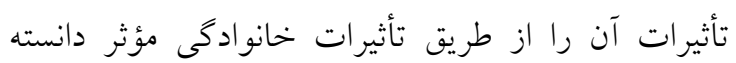

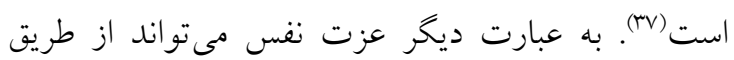

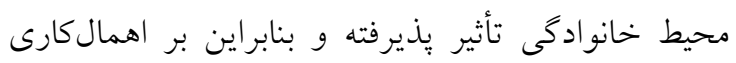

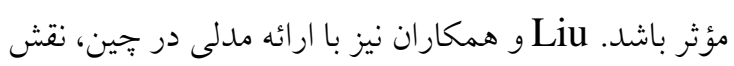
عزت نفس را اهمال كارى تحصيلى دانشجويان بيان كرده اند. آنها بيان مى كنند كه عزت نفس دانشجويان در خانو اده

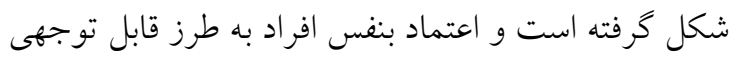

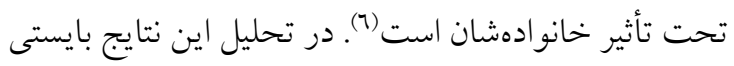

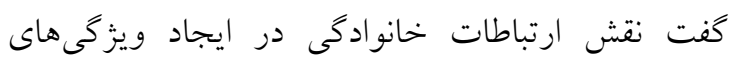

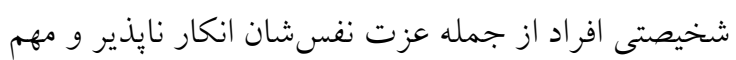

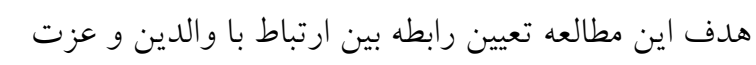
نفس با اهمال كارى تحصيلى بوده است. نتايج نشان دهنده

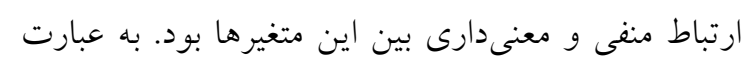

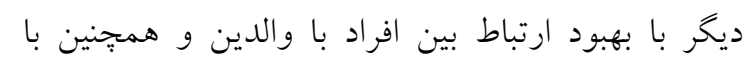

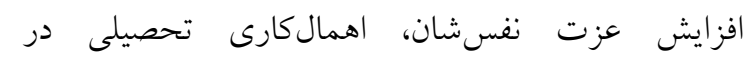

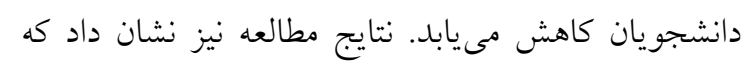

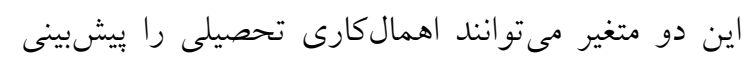
Klasen كارى و تعللوورزى با عزت نفس رابطه منفى معنى دارى

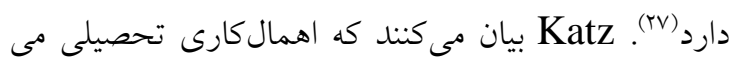
تواند باعث بيامدهاى شناختى و هيجانى منفى از جمله

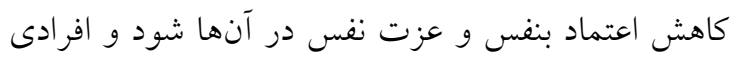
كه عزت نفس بايين دارند جهت محافظت از خود دست

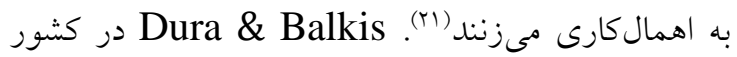
تركيه نيز بيان مى كنند كه عزت نفس مارس يك عامل مهم در

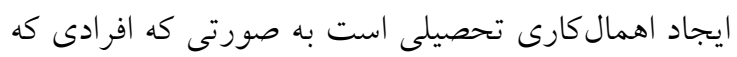

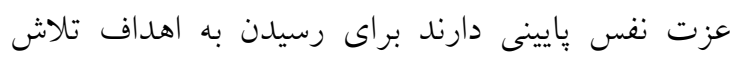
نكرده جون آنها ترس از شكست را به طور غير واقعبينانه

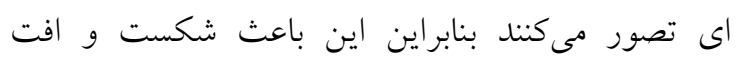
تحصيلى آنها مىشود جين عزت نفس را به عنوان يك متغير مئى ميانجى بين خودكار آمدى و اهمال كارى تحصيلى مى داند (^). مطيعى نيز در مطالعهاش به بررسى عوامل مؤثر در اهمالكارى

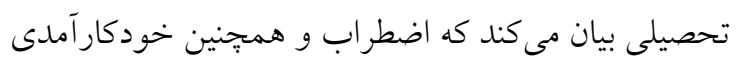

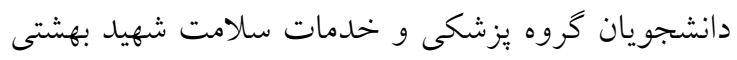

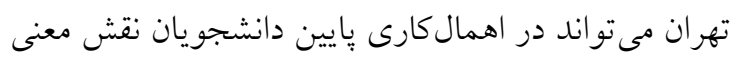

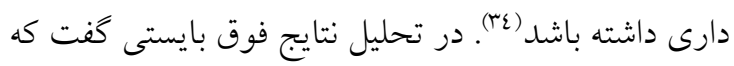
مطالعهاى در جهت مخالف نتايج مطالعه حاضر در زمينه

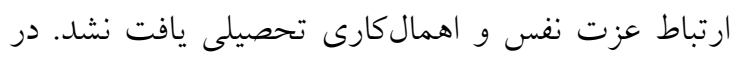

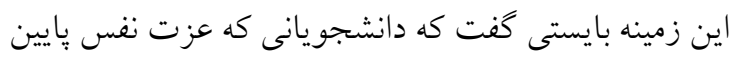
دارند به دليل احساس شكست در دستيابى به اهدافشان احساس ترس داشته و دجار اهمالكارى تحصيلى مى دى 
از محدوديتهاى اين مطالعه مىتوان به روش نمونه كيرى

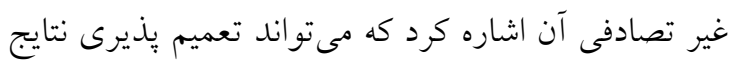

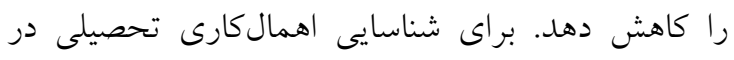

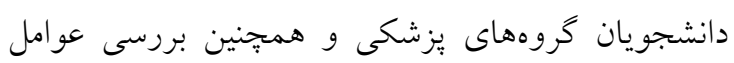

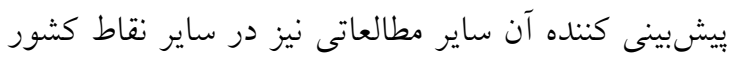

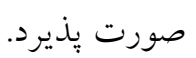

نتايج مطالعه حاضر نشان داد كه با افزايش عزت نقد نفس و

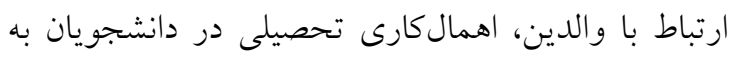

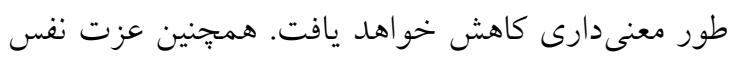

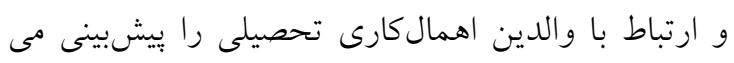

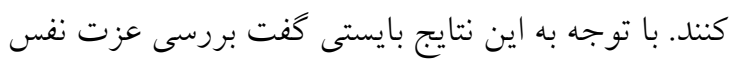

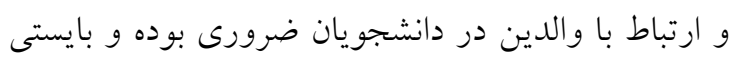
در سيستمهاى آموزشى با آموزش مناسب، اين متغيرها

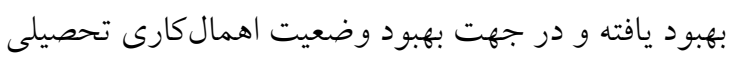

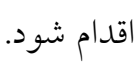
نتايج مطالعه فوق بايستى توسط مديران سيستمهاى

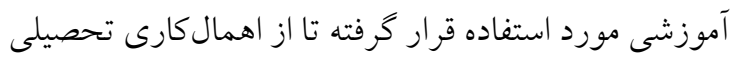

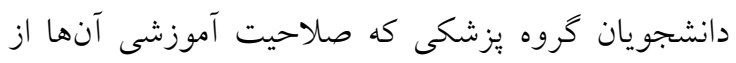
اهميت بالايى برخوردار است، خوددارى شود. استفاده از

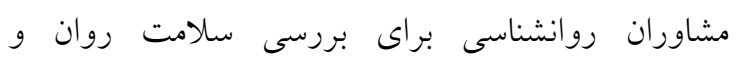

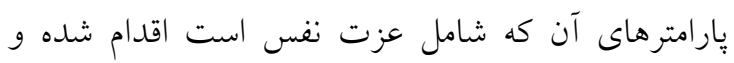
دانشجويان در معرض خطر شناسايى شوند. هم:نهنين شناسايى روابط مختل شده دانشجويان با والدين خواهد توانست نقش مهمى در بهبود سلامت روان و كاهش اهمال

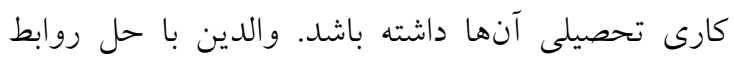
مختلف شده و ايجاد جوى سالم در خانواده مى توانند در

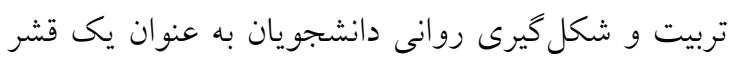

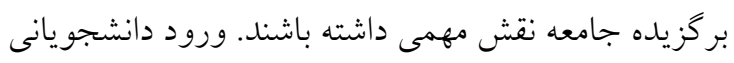

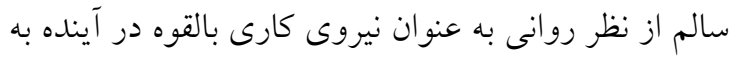

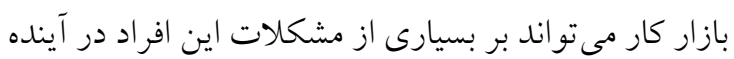

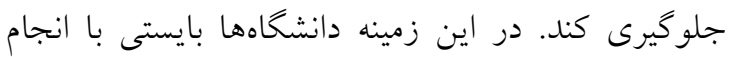
مشاورهاى روانى مختلف در زمينه شناسايى روابط بين

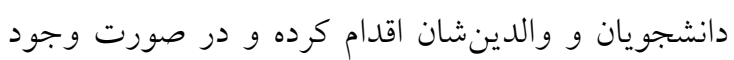

ميانخين نمره اهمال كارى تحصيلى در اين مطالعه در حد

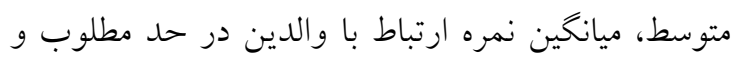

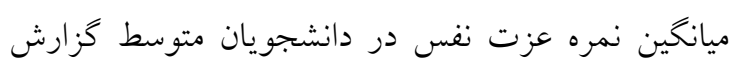

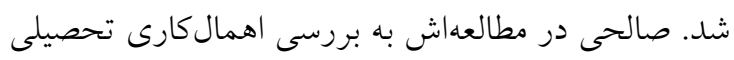

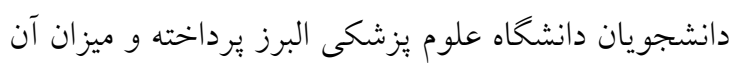

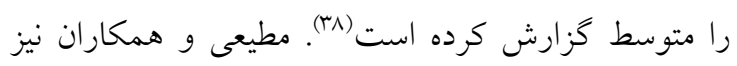
ميزان اهمالكارى تحصيلى در دانشجويان يزشكى شهيد

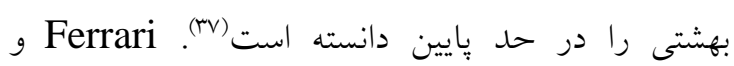

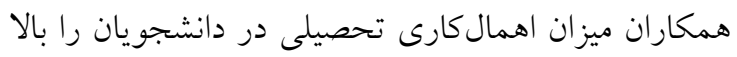

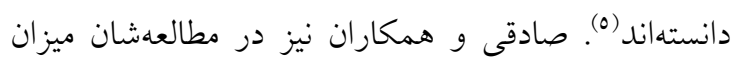

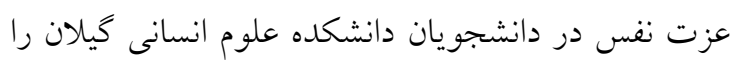

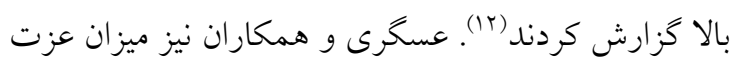
نفس در بعد تحصيلى در دانشجويان بزشكى در كيلان را

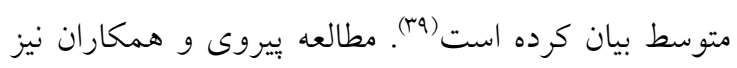

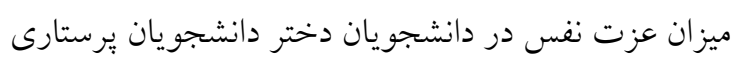

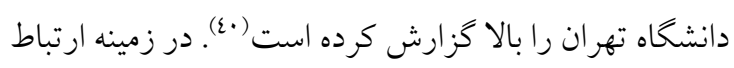

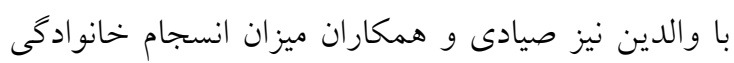

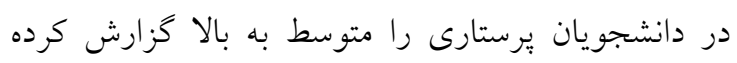

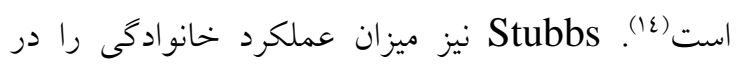

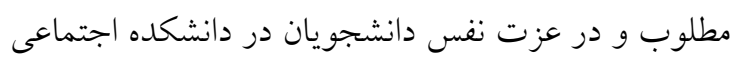

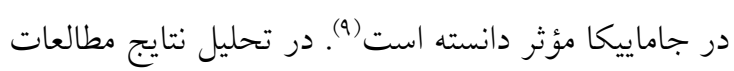
فوق بايستى كفت ميزان اهمالكارى بيشتر دانشجويان

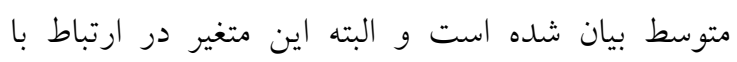

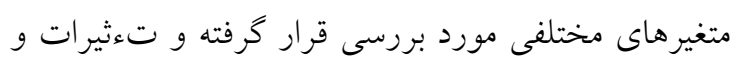

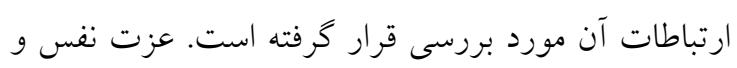
ارتباط با والدين نيز در بيشتر مطالعات صورت كرفته بر برد روى دانشجويان در طيف متوسط به بالا بوده است. با توجه به اين كه كروه مورد بررسى دانشجويان هستند، آنها دوران

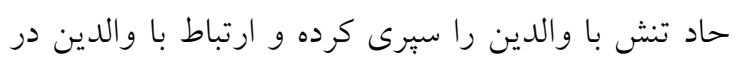

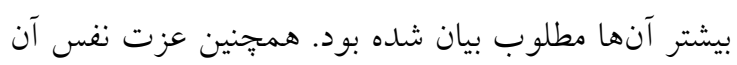

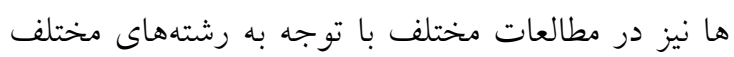

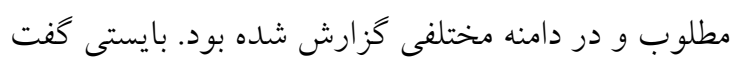

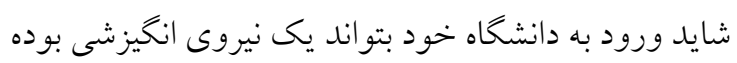
و باعث افزايش عزت نفس دانشجويان شود. 


$$
\begin{aligned}
& \text { اين يزوهش به صورت طرح تحقيقاتى به شماره rqV^ در }
\end{aligned}
$$

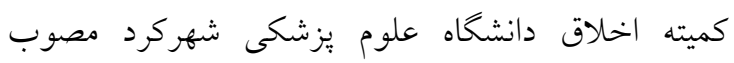

$$
\begin{aligned}
& \text { كرديلده است. بدين وسيله از معاونت يُزوهشى دانشئاه }
\end{aligned}
$$

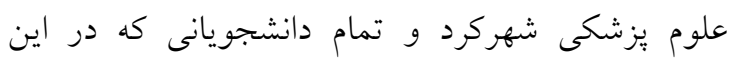

$$
\begin{aligned}
& \text { يزوهش ما را يارى نمودند، تشكر مىنماييم. }
\end{aligned}
$$

$$
\begin{aligned}
& \text { مشكل در جهت برطرف شدن اين مشكلات و در نتيجه } \\
& \text { بهبود سالمت روانى دانشجويان اقدام نمايند. } \\
& \text { تعارض منافع: هيجگگ نه تضاد منافعى بين نويسندكان اين } \\
& \text { مقاله وجود ندارد. }
\end{aligned}
$$

تقدير و تشكر

\section{References}

1. Noroozi S .The relationship between academic procrastination and self-esteem. Extension Scientific Quarterly of Promoting science. 2014;7(3):63-69. [Persian]

2. Custer NR. Test anxiety and academic procrastination among pre-licensure nursing students. Indiana University of Pennsylvania; 2016;39(3):162-3.

3. Cerino ES. Relationships Between Academic Motivation, Self-Efficacy, and Academic Procrastination. Psi Chi Journal of Psychological Research. 2014;19(4):156-63.

4. Savari K. An investigation of the prevalence of academic procrastination among male and female students of Ahwaz Payame Noor University. Social Cognition. 2013;1(2):62-8. [Persian]

5. Ferrari JR, O'Callaghan J, Newbegin I. Prevalence of procrastination in the United States, United Kingdom, and Australia: arousal and avoidance delays among adults. North Am J Psychol. 2005;7(1):1-6.

6. Liu G, Cheng G, Hu J, Pan Y, Zhao S. Academic self-efficacy and postgraduate procrastination: a moderated mediation model. Frontiers in psychology. 2020;11:1752.

7. Balkis M, Duru E. The Evaluation of the Major Characteristics and Aspects of the Procrastination in the Framework of Psychological Counseling and Guidance. Educ Sci: Theory \& Practice. 2007;7(1):376-85.

8. Tan JF, Ma ZW, Li XT. Global self-esteem mediates the effect of general self-efficacy on Chinese undergraduates' general procrastination. Social Behav Person: an international journal. 2015;43(8):1265-71.

9. Shekera Stubbs N. Family functioning and academic self-efficacy among sixth form and community college students in Barbados and St. Lucia. Int J Learn Higher Educ. 2015;22(4):35-48.

10. Alizadeh S, Namazi A, Kouchakzadeh TS. A Comparative Study of self-esteem in nursing and midwifery students of Islamic Azad University of Rasht and its correlation with academic success. Journal Of Nursing Education (JNE). 2016; (4):17-25. [Persian]

11. Ariyanpooran S, Amiri Manesh M, Taghavi D, Haghtalab T. Relationship between self-concept and academic motivation (reading, writing and math) in elementary students with LD. Journal of Learning Disabilities. 2014;4(1):56-72. [Persian]

12. Sadeghi A, Asghari F, Saadat S, Kupas EN. The Relationship between Family Cohesion and Coping Strategies with Positive Attitude to Addiction among University Students. Asian Journal of Research in Social Sciences and Humanities. 2014;4(11):285-94. [Persian]

13. Hossein Khanzadeh AA, Asghari F, Shakerinia I. The role of family cohesion in prediction of aggressive behaviors of children. Quarterly Journal of Child Mental Health. 2015;2(2):73-84. [Persian]

14. Sayyadi M, Vahabi A, Sayyadi S, Kashefi H, Vahabi B. The relation between family cohesion and academic self efficacy in Kurdistan University of Medical Sciences students', 2016. Scientific Journal of Nursing, Midwifery and Paramedical Faculty. 2017;3(1):31-42. [Persian]

15. Parhizgar A, Mahmodnia AR, Mohammadi S. A Comparative Study of Relationship between, Child-Parent's Relation and Identity Crisis and Lack of Identity Crisis in Female High School Students. Journal of Applied Psychology. 2009;2(10): 82-93. [Persian]

16. Atadokht A. Sleep quality and its related factors among university students. Journal health and care. 2015;17(1):9-18. [Persian]

17. Hadadvand M, Karimi L, Abbasi Validkandi Z, Ramezanian P, Mehrabi H, Zeighami Mohammadi S. The Relationship between Internet Addiction and Sleep Disorders in Students. Journal of Health And Care. 2013;15(4):39-49. [Persian] 
18. Chehrzad MM, Ghanbari A, Rahmatpour P, Barari F, Pourrajabi A, Alipour Z. Academic procrastination and related factors in students of Guilan University of Medical Sciences. The Journal of Medical Education and Development. 2017;11(4):352-62. [Persian]

19. Kandemir M. Predictors of academic procrastination: coping with stress, internet addiction and academic motivation. World Appl Sci J. 2014;32(5):930-8.

20. Odaci $\mathrm{H}$. Academic self-efficacy and academic procrastination as predictors of problematic internet use in university students. Computers \& Education. 2011;57(1):1109-13.

21. Katz I, Eilot K, Nevo N. "I'll do it later": Type of motivation, self-efficacy and homework procrastination. Motivation and Emotion. 2014;38(1):111-9.

22. Dryden W. Dealing with procrastination: The REBT approach and a demonstration session. $J$ Rational-Emotive Cognitive-Behav Therapy. 2012;30(4):264-81.

23. Vahidi far H, Nabavi Zadeh, Ardebily fard M. Assessment of internet addiction among college students in North Khorasan University of Medical Sciences in Bojnoord, Iran. Journal of North Khorasan University of Medical Sciences. 2013;5(Student Research Committe Supplementary):1081-8. [Persian]

24. Vazpour S, Esmaeeli M, Hassan Nia S, Azami Y. The relationship of parenting patterns and birth order with procrastination in high school girl students of Amol city. Journal of Educational Psychology Studies. 2014;11(20):197-216. [Persian]

25. Grolnick WS. The role of parents in facilitating autonomous self-regulation for education. Theory Res Educ. 2009;7(2):164-73.

26. Esmaeili N, Monadi M. Identifying the causes of academic procrastination from the perspective of male middle school male students. International Journal of Humanities and Cultural Studies (IJHCS) ISSN 2356-5926. 2016:2464-87.

27. Klassen RM, Krawchuk LL, Rajani S. Academic procrastination of undergraduates: Low selfefficacy to self-regulate predicts higher levels of procrastination. Contemp Educ Psychol. 2008;33(4):915-31.

28. Solomon LJ, Rothblum E. Procrastination assessment scale-students. Dictionary of behavioral assessment techniques. 1988:358-60.

29. Jokar B, Delavarpour M. The relationship between educational proclivity and developmental goals. New Educational Ideas. 2007;3(3-4 ):61-80. [Persian]

30. Rosenberg M. Society and the adolescent self-image. Princeton, NJ: Princeton University Press.1965.

31. Greenberger E, Chen C, Dmitrieva J, Farruggia SP. Item-wording and the dimensionality of the Rosenberg Self-Esteem Scale: Do they matter?. Person Indiv Differ. 2003;35(6):1241-54.

32. Mohammadi N. The preliminary study of validity and reliability of Rosenberg's self-esteem scale. Quarterly journal of Iranian psychologists. 2005;4:55-62. [Persian]

33. Fine MA, Moreland JR, Schwebel AI. Long-term effects of divorce on parent-child relationships. Developmental Psychology. 1983;19(5):703.

34. Motie H, Heidari M, Bagherian F, Zarani F. Determining Factors of Academic Procrastination. Sadra Medical Journal. 2018;6(4):275-86. [Persian]

35. Rosário P, Costa M, Núñez JC, González-Pienda J, Solano P, Valle A. Academic procrastination: Associations with personal, school, and family variables. Span J Psychol. 2009;12(1):118-27.

36. Kim KR, Seo EH. The relationship between procrastination and academic performance: A metaanalysis. Person Indiv Differ. 2015;82:26-33.

37. Motie H, Heidari M, Sadeghi MA. Predicting academic procrastination during self-regulated learning in Iranian first grade high school students. Procedia-Social and Behavioral Sciences. 2012;69:2299-308.

38. Salehi L. Application of "Social Cognition Theory" in predicting the factors affecting academic procrastination among students of Alborz University of Medical Sciences in 2017 . Journal of Medical Education and Development. 2018;12(4):274-85. [Persian]

39. Asgari F, Mirzaee M, Tabari R, Kazemnejad Leili E. Self-esteem in students of Guilan University of Medical Sciences. Research in Medical Education. 2016;8(2):18-26. [Persian]

40. Peyrovi H, Ghezelbash S, Ghorbani A, Inanloo M, Alizadeh H, Haghani H. Relationship between self esteem and demographic variables among undergraduate student nurses. Journal of Health and Care. 2012;14(4):52-61. [Persian] 